Research Article

\section{Anatomical changes of the development of red Sokoto goat stomach}

\author{
Bello $\mathrm{A}^{1 *}$, Joseph $\mathrm{OA}^{1}$, Onua $\mathrm{JE}^{1}$, Onyeanusib $\mathrm{BI}^{2}$, Umaru $\mathrm{MA}^{4}$ and \\ Bodinga $\mathrm{HA}^{3}$
}

\author{
'Department of Veterinary Anatomy, Usmanu Danfodiyo University, Sokoto, Nigeria \\ 2Department of Veterinary Anatomy, Ahmadu Bello University Zaria, Nigeria \\ ${ }^{3}$ Department of Veterinary Surgery and Radiology, Usmanu Danfodiyo University, Sokoto, Nigeria \\ ${ }^{4}$ Department of Theriogenology and Animal production, Usmanu Danfodiyo University, Sokoto, Nigeria
}

\section{Abstract}

This study is aimed at investigating the age related changes in postnatal development of red Sokoto goat stomach. In this study, a total of ten red Sokoto goat digestive tract samples were used and they were grouped into five (5) age categories (group A to E). The goat ages were estimated using dentition eruption and wearing. The stomach was identified and separated from the other part of digestive tract. The gross study revealed that the stomach was composed of four (4) segments that named; rumen, reticulum, omasum and abomasum with anatomical demarcations between them. The biometric study of weight, length, width, thickness, and volume was found to be increasing with advancement in postnatal ages with the following valves shows the mean value of weight, length, width, thickness and volume were to be 29 to $58.0(\mathrm{~g}), 23.5$, to $52.1(\mathrm{~cm})$, 15.4 to $29.0(\mathrm{~cm}), 0.48$ to $1.0(\mathrm{~mm})$ and102 to $432\left(\mathrm{~cm}^{3}\right)$ from group A to group E respectively. Based on the above findings it was suggested that more research should be conducted using histological techniques and electron microscopy in order to finalize on the findings.

\section{More Information}

*Address for Correspondence: Bello $A$, Department of Veterinary Anatomy, Usmanu Danfodiyo University, Sokoto, Nigeria, Tel: +234(0)8039687589;

Email: abccrcfge28@gmail.com

Submitted: 18 February 2020

Approved: 03 March 2020

Published: 04 March 2020

How to cite this article: Bello A, Joseph OA, Onua $\mathrm{JE}$, Onyeanusib BI, Umaru MA, et al. Anatomical changes of the development of red Sokoto goat stomach. Insights Vet Sci. 2020; 4: 004-009.

DOI: 10.29328/journal.ivs.1001019

Copyright: (C) 2020 Bello A, et al. This is an open access article distributed under the Creative Commons Attribution License, which permits unrestricted use, distribution, and reproduction in any medium, provided the original work is properly cited.

Keywords: Age; Rumen; Development; Stomach; Red Sokoto Goat; Reticulum; Omasum

Check for updates

OPEN ACCESS

\section{Introduction}

The ruminant stomach is a multi- chamber organ when compared to mono-gastric [1]. It is usually composed of four separate chamber (Rumen, Reticulum, Omasum and Abomasum) and allows digestion of large quantity of plant materials that will be relatively indigestible for most other types of mammals. The entire stomach believes to have been divided into forestomach (Rumen Reticulum and Omasum.) and glandular stomach (Abomasum). Each of the chambers has a very distinctive characteristic. The forestomach which is involved in breakdown of feed and serves as the primary site for microbial fermentation and is the largest part of the ruminant stomach [2]. There are two main type of goats in the Sudan savanna, the red Sokoto goat and the Sahelian. The red Sokoto goat is predominantly reddish brown in colour and there are over 17 million individuals and they are value for their skin which is used for the internationally recognized morocco leather [3]. The kids of red Sokoto goat weigh between $1.5-2.0 \mathrm{~kg}$ at birth while the adult weigh $20-35 \mathrm{~kg}$ [4].

Goats constitute a very important part of the rural economy in Nigeria, with more than $95 \%$ of the rural households keeping goats [5]. As a multipurpose animal, goats provide meat, milk, hides and they rank next to cattle in income generation and their meat (Chevon) is quite popular and well relished. The stomach of a goat is very large and consists of four parts. The rumen, the reticulum, the Omasum and the abomasum. The rumen occupies almost all of the left half of the abdominal cavity. It is divided internally into compartments by pillars (large folds of the wall) and lined with many papillae (small projections of tissue). The rumen wall has a layer of muscle. The reticulum is the foremost part of the stomach. It lies beneath ribs $6-8$, just behind the diaphragm and liver. Its lining is arranged in a mesh-like 'honeycomb' pattern. The omasum is the smallest part of the stomach. It is oval in shape and sits on the right side of the abdominal cavity. Its interior is divided by large longitudinal folds of tissue, like pages in a book. The abomasum is about twice the size of the reticulum, but elongated in shape. It lies on the right side of the abdominal cavity. The abomasum is the ruminants true or glandular stomach [6].

Ruminants digestive systems covert low quality fibrous and other feedstuffs into highly nutritious meat and milk. In total these systems produce 30 and $100 \%$ of the world supply of these meat and milk product (FAO 2008a) because these systems play an important role in the world food supply. It is crucial to understand the age related changes in development 
of ruminant stomach in order to solve problems associated with digestion and absorption in various compartment of ruminant stomach and to understand the growth increment to enhance the nutrient in various age group of the animal. Therefore, increasing the potential and productivity of small ruminants' stomach especially goat through knowing the rate of growth could go a long way in meeting the world demand for animal protein.

The aim of this work is to study the age related changes associated with the development of red Sokoto goat stomach through gross examination and histologically observation of various compartment of the stomach (Rumen, Reticulum, Omasum and Abomasum) postnatal. These will be achieved through the following Objectives;

To determine the gross feature of the various segment of the organs (Rumen, Reticulum, Omasum and Abomasum) in relation to the various ages of the animal.

To determine the biometric data of the various segment of the organ (Rumen, Reticulum, Omasum and Abomasum) in relation to the various age of the animals.

To determine the level of development (length, width, thickness, volume) of the various organ of the stomach component (Rumen, Reticulum, Omasum and Abomasum) in relation to the various age of the animal.

\section{Materials and methods}

The study was conducted in Sokoto metropolis, the capital of Sokoto state of Nigeria. Sokoto state geographically was located on $12^{\circ} 15 \mathrm{~N}$ and $05 \mathrm{E}$ latitude, and $38 \mathrm{~m}$ above sea level. The state has savannah vegetation of short grasses in the south and thorns in the north. Sokoto was bounded by Zamfara State to the east, Niger Republic to the north and Kebbi state to the West and southwest [7]. The state was ranked second in the nation livestock population with an estimated number of 34,532 horses, 51,388 donkeys, [8]. 2 million cattle, 1.85 million sheep, 2 million goats, 0.8 million camels, 4 million chickens and 3.2 million poultry.

Entire tubular digestive system from ten (10) healthy animal of either sex were used in this study. The animal digestive tract was purchased from Wammako market at Wammako Local Government, and transported to the Gross Anatomy Laboratory of the Department of Veterinary Anatomy, Usmanu Danfodiyo University, Sokoto. The animals were observed before slaughting to ascertain the age of the animals. The digestive tract was dissected out from the abdominal cavity then the Whole stomach (Rumen, Reticulum, Omasum, Abomasums) was removed from the entire digestive system.

\section{Gross observation}

The component of the sampled stomach was observed thoroughly base on shape size, and colour of each organ in situ and separately, internally and externally with the help of eyes and hand lens.

\section{Biometric}

The sample were assigned into five postnatal groups according to their age variation.

0-6 month as group A

6 months - l year as group B

l - 2 years as group C

2 - 3 years as group D

Above 3 years as group $\mathrm{E}$

The vital measurement of length, width, thickness and volume and spleen were taken with landmarks as designated as follows:

A. Length of the greater curvature (Rumen) along the long axis.

B. Length of the lesser curvature (Rumen) along the short axis.

C. Width of the Rumen: This was taken from the dorsal to ventral side of the rumen using measuring tap.

D. Thickness of the Rumen: This was taken from the surface of the rumen to the interior wall of the segment using micrometer screw gauge.

E. Volume of the Rumen: This was taken as the entire volume of the rumen using water displacement technique (Achimidic principle).

F. Weight of the Rumen: This was tone by taken the weight of the rumen using digital weighing balance with the sensitivity of $0.01 \mathrm{~g}$.

G. Length of the Reticulum along the long axis.

H. Width of the Reticulum: This was taken from the dorsal to dorsal side of the reticulum using measuring tape.

I. Thickness of the Reticulum: This was taken from the surface of the reticulum to the interior wall of the segment using micrometer screw gauge.

J. Volume of the Reticulum: This was taken as the entire volume of the reticulum using water displacement technique (Achimidic principle).

K. Weight of the Reticulum: This was tone by taken the weight of the reticulum using digital weighing balance with the sensitivity of $0.01 \mathrm{~g}$.

L. Length of the Omasum along the long axis. 
M. Width of the Omasum: This was taken from the dorsal to dorsal side of the Omasum using measuring tape.

N. Thickness of the Omasum: This was taken from the surface of the Omasum to the interior wall of the segment using micrometer screw gauge.

O. Volume of the Omasum: This was taken as the entire volume of the Omasum using water displacement technique (Achimidic principle).

P. Weight of the Omasum: This was tone by taken the weight of the Omasum using digital weighing balance with the sensitivity of $0.01 \mathrm{~g}$.

Q. Length of the Abomasum along the long axis.

R. Width of the Abomasum: This was taken from the dorsal to ventral side of the abomasum using measuring tape.

S. Thickness of the Abomasum: This was taken from the surface of the abomasum to the interior wall of the segment using micrometer screw gauge.

T. Volume of the Abomasum: This was taken as the entire volume of the abomasum using water displacement technique (Achimidic principle).

U. Weight of the Abomasum: This was tone by taken the weight of the abomasum using digital weighing balance with the sensitivity of $0.01 \mathrm{~g}$.

V. Length was taken as the greater distance with the help of butterfly measuring tape width of each organ was taken as the shortest distance with the help butterfly measuring tape, thickness was taken as the average thickness of the organ from the inferior to the superior surface of the organ using micrometer screw gauge and Vernier caliper volume of each organ was taken as the method adopted by achimidies principle using water displacement technique.

\section{Ageing in ruminants}

Ruminant age determination was carried out using knowledge of eruption and wearing of milk teeth and permanent teeth, as well as other anatomical features such as increase interdental space and change in shape of teeth, angulation of the teeth, degree of wearing of the teeth.

\section{Data presentation}

Data obtained were processed and presented in mean \pm standard error of mean (mean \pm S.D) using Microsoft excel software 2017.

\section{Results and discussion}

\section{Gross observation}

A total of Ten (10) samples were used in the study, seven (7) were female and three (3) male. There was no sex consideration while conducting the study. The entire stomach occupied almost 3/4 of abdominal cavity and is surrounded by visceral peritoneum. It consists of the Following four parts, rumen, reticulum, omasum and abomasum. Rumen, which accounted for $75 \%-78 \%$ of the entire stomach, was the largest, following by the abomasum, omasum and reticulum, successively. The first three parts were commonly known as fore stomach (plate I).

Rumen: Rumen shape is like a flattened sac shown incomplete U-shape, in all the age group. There were sulcus cranials and sulcus caudalis in the front and rear end and sulcus ruminissinster and sulcus ruminisin the left and right side which is more visible at 2-3 year age group (plate II). The ventral sac round left longitudinal groove spleen was observed, the interface between rumen and reticulum was about $2 \mathrm{~cm}$ in diameter, in which was the vestibular of rumen in shape of pleats, it was the anterior column behind the vestibular (plate II) Most of mucosa covered with dense papillae at the surface, especially abdominal sac, was brown or black. But the edge of adductor muscle was pale, and the mucosa of caudal sac was gray in above 3 year age group.

Reticulum: Reticulum was located in the forefront of rumen, like a pear shape with smooth contour the reticulum is adjacent to the diaphragm, lungs, abomasums, rumen and liver. The heights of the reticular crests and depth of the structures vary across the various age group.

Ostiumreticulo-omasicum located in the small bend of

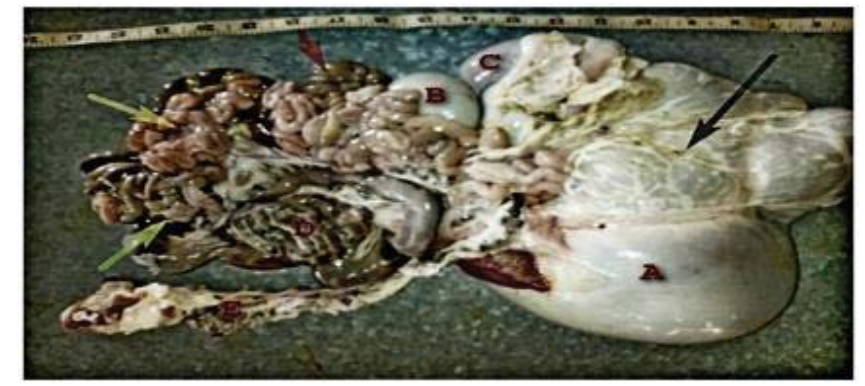

Plate I: Photograph showing the digestive tract of Red Sokotogoatat 2-3 years shows A: Rumen; B: Omasum; C: Abomasum; D: Colon; E: Rectum; (black arrow): Omentum; (red arrow): Duodenum; (yellow arrow): Jejunum; (green arrow): lleum.

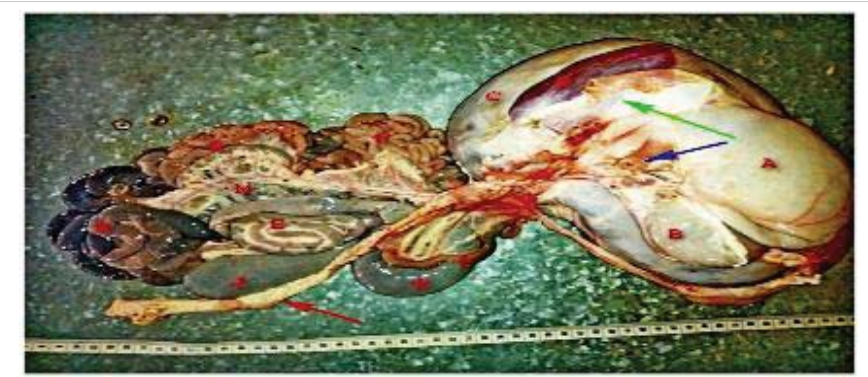

Plate II: Photograph showing the digestive tract of Red Sokoto Goat at 1-2 years shows A: Rumen; B: Omasum; C: Abomasum; D: Spleen; E:colon; F:jejunum, H; ileum I;duodenum J;caecumK;jejunum;M;mesentry (Blue arrow): oesophagus; (green arrow):diaphragmatic sheath,( Red arrow);rectum. 
reticulum was a circular opening, about $2 \mathrm{~cm}$ in diameter, in 2-3 years' age group and had approximately 3-4 $\mathrm{cm}$ above the basal reticulum toward the right side of the body midline. Furthermore, the lip of sulcus reticuli was looked upon as the boundary of the bottom edge of opening and side edge of ostiumreticulo-omasicum. Sulcus reticuli, also known as sulcus esophageus (Plate II).

Omasum: The omasum, lying in the middle right side of the abdominal cavity, was oval in shape and the oblique wall of omasum located in right front of diaphragmatic liver is observed in above 3 years' age group meanwhile, the faciesvisceral is was contact with reticulum, rumen and abomasum. Fundus of omasum was located in the lesser curvature toward right rear of omasum's bend, and the upper and lower ends of lesser curvature leading to reticulum and abomasum, respectively (Plate III). Furthermore, the sulcus omasi was extending along the cavity surface of lesser curvature, where liquid and small particles feed would directly flow into abomasums from reticulum.

Abomasum is located along the ventral midline of the stomach. It starts from the communication with the omasum and ends by the communication with the small intestine called pylorus, there a powerful sphincter (a circular muscle) is present and more gross observed at above 3 years of which allow the transit of the ingesta to pass from the abomasum into the small intestine only by a reflex act. Also in all the age categories, as in all ruminants, the pyloric sphincter forms a protuberance called torus pyloricus (Plate IV).

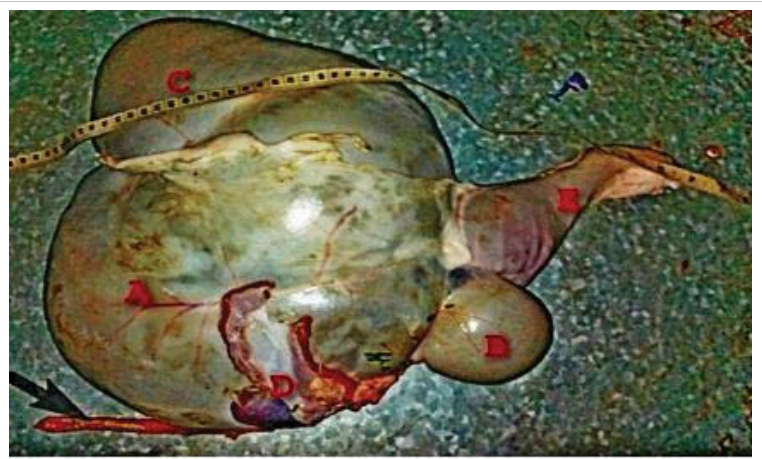

Plate III: Photograph showing the stomach of Red Sokoto Goat at 1-2 years shows A: Rumen; B: Reticulum; C: Omasum; D: Abomasum; Spleen E: Abomasum.

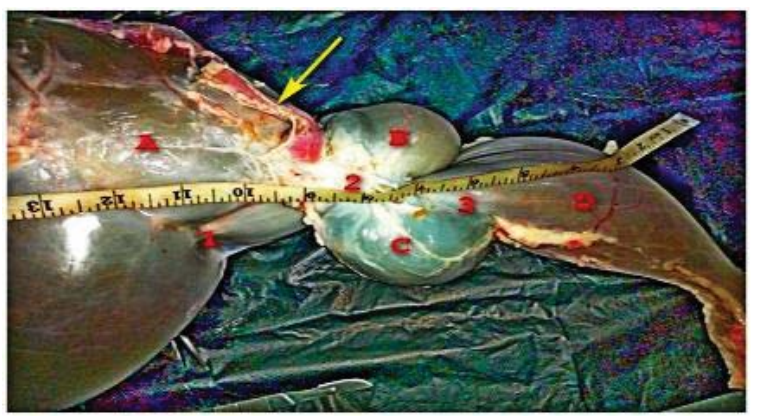

Plate IV: Photograph showing the stomach of red Sokoto goat above 3years shows A: Rumen; B: Reticulum; C: Omasum; D: Abomasum; 1: rumenioreticular joint; 2: Omasum-reticular joint; 3: omasumabomasal junction yellow arrow; esophagus.
Surface expansion coefficient of rumen: In Red Sokoto goat, the surface expansion coefficient (SEF) of papillae in rumen mucosa was on average 0.1-1.2 degree of size and density of papillae varied considerably in different age categories, so the value of SEF was relatively large difference as the animal increase in age For example, on the dorsal wall, even though the degree of density was not same in 0-6 month age group, the size of papillae was smaller in general, corresponding to the smallest SEF compared to 6-1 year age group, Comparing with the dorsal wall however, the thick and full papillae were densely distributed on ventral wall which is seen in above 3 year of age Although the height and diameter of some papillae on the floor of dorsocaudal blind sac even more than the dorsal wall's, the density is relatively sparse. Yet the SEF was greater than 2-3. The density of papillae on the cranioventral floor of atrium was comparatively large but the shape was lower than ventral wall (Plate V).

\section{Biometric observation}

The biometric study of Red Sokoto Goat shows that the stomach had different in the mean, weight value at different age categories in which there is an increase in the value with age. Also the mean value of the Rumen, Reticulum, Omasum and Abomasum in weight, length, width thickness and volume increase with age that is at different various postnatal age categories from group A to group E respectively. Biometrically, the weight, length, width and volume of the samples were observed and analyzed as mean \pm S.D. Weight value of the rumen were found to range between $116 \pm$ SD to $540 \pm$ SD and the mean value of length, width, thickness and volume were to be $29 \pm$ SD to $58.0 \pm$ SD, $23.5 \pm \mathrm{SD}$, to $52.1 \pm \mathrm{SD}, 15.4 \pm \mathrm{SD}$ to $29.0 \pm$ SD, $0.48 \pm$ SD to $1.0 \pm$ SD and102 \pm SD to $432 \pm$ SD from group A to group E respectively.

The result revealed that the mean weight of the digestive tract, stomach and various segment of the stomach (rumen, reticulum, omasum and abomasum) tends to increase with age that is from group $\mathrm{A}$ to group $\mathrm{E}$ as in the rumen.

However, there is variation in the mean weight, length, width, thickness and volume of various segments that is

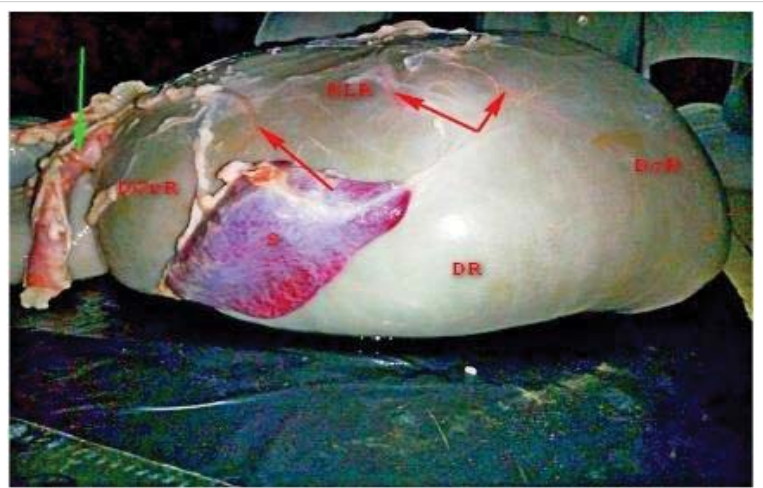

Plate V: Dorsal cranial artery of the rumen S; Spleen, dorsal caudal artery of the Rumen Green arrow; oesphagus. RLR: Right lateral rumen, DcR: Dorsal caudal rumen, DCrR: Dorsal cranial rumen. 
rumen, reticulum, omasum and abomasum with the rumen had larger value compare to the reticulum, omasum and abomasum as shown in the table 1.1, 1.2, 1.3, 1.4 and 1.5.

There is significant variation of weight, length, width, thickness and volume of each part of stomach in the red Sokoto goat at different postnatal ages categories may be due to increase feed consumption, high contents of roughages in their diet which need more time and large area to digest.

This research work showed that the stomach of Red Sokoto Goat occupied the entire left part of abdominal cavity, is very large and consists of four parts. The rumen, the reticulum, the Omasum and the abomasum and this is in line with the finding. On morphological features of the stomach in the adult yak $[9,10]$.
The rumen occupies almost all of the left half of the abdominal cavity. It is divided internally and lined with many papillae. The rumen wall has a layer of muscle. The reticulum is the foremost part of the stomach. It lies beneath ribs 6-8, just behind the diaphragm and liver. Its lining is arranged in a mesh-like 'honeycomb' pattern. The Omasum is the smallest part of the stomach. It is oval in shape and sits on the right side of the abdominal cavity.

Its interior is divided by large longitudinal folds of tissue, like pages in a book. The abomasum is about twice the size of the reticulum, but elongated in shape. It lies on the right side of the abdominal cavity. The lower end of the abomasum is constricted by the pyloric sphincter, a strong muscular valve which separates it from the duodenum sphincter, a strong muscular valve which separates it from the duodenum.

Table 1.1: Mean \pm SD value of the rumen in relation to various postnatal Ages.

\begin{tabular}{|c|c|c|c|c|c|}
\hline Age & Group A & Group B & Group C & Group D & Group E \\
\hline Weight (g) & $116 \pm 13.88$ & $246 \pm 25.60$ & $256 \pm 11.31$ & $281 \pm 16.01$ & $540 \pm 14.60$ \\
\hline Length of greater curvature(cm) & $29.01 \pm 1.41$ & $34.65 \pm 0.49$ & $41.2 \pm 0.65$ & $48.5 \pm 7.77$ & $58.0 \pm 1.65$ \\
\hline Length of lesser curvature(cm) & $23.5 \pm 3.53$ & $27.2 \pm 1.42$ & $35.5 \pm 0.70$ & $42.1 \pm 8.48$ & $52.1 \pm 5.65$ \\
\hline Width $(\mathrm{cm})$ & $15.4 \pm 1.69$ & $15 \pm 1.22$ & $17 \pm 1.05$ & $18 \pm 0.49$ & $29 \pm 6.15$ \\
\hline Thickness(cm) & $0.48 \pm 0.06$ & $0.5 \pm 0.04$ & $0.6 \pm 0.09$ & $0.8 \pm 0.04$ & $1 \pm 0.24$ \\
\hline Volume $\left(\mathrm{cm}^{3}\right)$ & $102 \pm 5.65$ & $232 \pm 2.82$ & $274 \pm 6.67$ & $283 \pm 4.24$ & $432 \pm 8.48$ \\
\hline
\end{tabular}

KEY: Group A-0-6 month; Group B- 6 month-1year; Group C- 1-2 years ; Group D -2-3 years; Group E-above 3 years.

Table 1 1.2: Mean \pm SD value of the reticulum in relation to various postnatal Ages.

\begin{tabular}{|c|c|c|c|c|}
\hline Age & Group A & Group B & Group C & Group D \\
\hline Weight $(\mathrm{g})$ & $34.9 \pm 3.58$ & $44.1 \pm 1.73$ & $56.5 \pm 2.85$ & $76.9 \pm 6.27$ \\
\hline length $(\mathrm{cm})$ & $13.7 \pm 1.65$ & $18.9 \pm 1.84$ & $24.8 \pm 3.33$ & $33.0 \pm 2.38$ \\
\hline Width $(\mathrm{cm})$ & $03.9 \pm 0.92$ & $05.3 \pm 1.62$ & $6.9 \pm 0.40$ & $11 \pm 1.32$ \\
\hline Thickness $(\mathrm{cm})$ & $02.3 \pm 0.14$ & $07.6 \pm 0.12$ & $1.61 \pm 0.26$ & $2.31 \pm 0.77$ \\
\hline volume $\left(\mathrm{cm}^{3}\right)$ & $25.5 \pm 0.65$ & $34.9 \pm 3.25$ & $43.8 \pm 2.40$ & $5.17 \pm 2.73$ \\
\hline
\end{tabular}

KEY:- Group A-0-6 month; Group B- 6 month-1 year; Group C- 1-2 years ; Group D -2-3 years; Group E-above 3 years.

Table 1 1.3: Mean \pm SD value of the Omasum in relation to various postnatal Ages.

\begin{tabular}{|c|c|c|c|c|c|c|}
\hline Age & Group A & Group B & Group C & Group D \\
\hline Weight $(\mathrm{g})$ & $13.07 \pm 1.53$ & $20 \pm 15.58$ & $28 \pm 0.72$ & $33 \pm 1.13$ \\
\hline length $(\mathrm{cm})$ & $13.13 \pm 1.22$ & $17.0 \pm 0.35$ & $20.7 \pm 1.30$ & $23.2 \pm 2.89$ \\
\hline Width $(\mathrm{cm})$ & $3.72 \pm 0.63$ & $6.84 \pm 0.62$ & $11 \pm 1.40$ & $16 \pm 0.69$ \\
\hline Thickness $(\mathrm{cm})$ & $0.58 \pm 0.05$ & $1.1 \pm 0.21$ & $2.4 \pm 0.63$ & $31 \pm 2.00$ \\
\hline volume $\left(\mathrm{cm}^{3}\right)$ & $20 \pm 1.14$ & $27 \pm 2.01$ & $29 \pm 3.59$ & $3.9 \pm 0.49$ \\
\hline
\end{tabular}

KEY:- Group A-0-6 month; Group B- 6 month-1 year; Group C- 1-2 years ; Group D -2-3 years; Group E-above 3 years.

Table 1 1.4: Mean \pm SD value of the abomasum in relation to various postnatal Ages

\begin{tabular}{|c|c|c|c|c|c|}
\hline Age & Group A & Group B & Group C & Group D & Group E \\
\hline Weight (g) & $25 \pm 1.32$ & $23 \pm 1.49$ & $27 \pm 1.37$ & $34 \pm 0.93$ & $47 \pm 8.48$ \\
\hline length(cm) & $11.41 \pm 1.38$ & $15 \pm 1.61$ & $17 \pm 1.73$ & $22 \pm 2.13$ & $27 \pm 4.50$ \\
\hline Width (cm) & $3.62 \pm 0.56$ & $5.74 \pm 1.55$ & $7.42 \pm 0.91$ & $12.56 \pm 2.19$ & $16.2 \pm 2.89$ \\
\hline Thickness(cm) & $0.33 \pm 0.14$ & $0.45 \pm 0.18$ & $0.56 \pm 0.21$ & $0.83 \pm 0.62$ & $1.15 \pm 0.42$ \\
\hline volume $\left(\mathrm{cm}^{3}\right)$ & $23.32 \pm 2.12$ & $31.23 \pm 3.47$ & $30.42 \pm 2.58$ & $32.54 \pm 5.48$ & $42.74 \pm 4.56$ \\
\hline
\end{tabular}

KEY:- Group A-0-6 month; Group B- 6 month-1 year; Group C- 1-2 years ; Group D -2-3 years; Group E-above 3 years.

Table 1 1.5: Mean \pm SD value of the spleen in relation to various postnatal Ages.

\begin{tabular}{|c|c|c|c|c|c|}
\hline Age & Group A & Group B & Group C & Group D & Group E \\
\hline Weight (g) & $10.32 \pm 2.82$ & $14.9 \pm 3.31$ & $20.41 \pm 4.274$ & $22.2 \pm 2.390$ & $28.6 \pm 4.95$ \\
\hline length(cm) & $3.81 \pm 0.78$ & $6.55 \pm 1.64$ & $7.92 \pm 0.50$ & $9.52 \pm 0.70$ & $13.12 \pm 1.41$ \\
\hline Width (cm) & $2.35 \pm 0.29$ & $4.56 \pm 0.48$ & $4.83 \pm 0.55$ & $6.95 \pm 0.35$ & $13.04 \pm 1.47$ \\
\hline Thickness(cm) & $3.86 \pm 0.57$ & $6.64 \pm 0.33$ & $6.74 \pm 0.47$ & $9.2 \pm 0.86$ & $1.84 \pm 3.67$ \\
\hline volume $\left(\mathrm{cm}^{3}\right)$ & $9.24 \pm 1.25$ & $11.5 \pm 1.76$ & $30.5 \pm 1.56$ & $20.7 \pm 2.51$ & $30.23 \pm 5.55$ \\
\hline
\end{tabular}


Its long axis reaches from a point opposite the ventral part of the $8^{\text {th }}$ intercostal space almost to the pelvic inlet was observed at 2-3 years of age.

The rumen is laterally compressed and extends from the abdominal roof to the floor and from left body wall across the midline, especially caudally and ventrally where it reaches the lower right flank it is externally separated from reticulum by a groove, and sacculated by muscular pillar into dorsal, ventral, caudodorsal, and candoventral sacs, the retriculum lies against the diaphragm, located more to the cranioventral surface of the rumen while the reticulum is observed to connect to the spherical omasum by a short tunnel. this finding is in line with the finding of [11].

It was also observed at lower age the rumen, reticulum and omasum are very tiny and at the entrance to the rumen there is a flap of skin fold like a grove that by pass. The rumen and lead directly to the abomasum generally the size relationship between rumen, reticulum and omasum increase as the animal grow's up while the abomasum is observed to be proportionally smaller.

\section{Conclusion}

The gross observation was concluded that the stomach of Red Sokoto goat situated in the left part of abdominal cavity. It composed of four segments (Rumen, Reticulum, Omasum and Abomasun) the significant increase of length, weight, width and volume was in the rumen compared to other part of the stomach.

\section{Recommendation}

Based on the above results it was recommended that further study on Age Related Changes on Postnatal Development of Goat Stomach should be conducted in different domestic species and breeds, in Nigeria for purpose of teaching and research in the world.

\section{References}

1. Aduku AO. Animal Nutrition in the tropics. Davon computer and Business Bureau Zaria, Nigeria. 2004; 10-31

2. Evans HE, De Lahunta A. Miller's Anatomy of the Dog 4th Edition, Elsevier-Health Science Division Philadelphia. 2012; 22

3. Gall CE. Goat breeds of the World $1^{\text {st }}$ Edition. 1996.

4. Osuhor CU, Alawa JP, Akpa GN. Research note: Manure Production by Goat Grazing Native Pasture in Nigeria. Tropical Grasslands. 2002; 36; 123-125.

5. Gilbert SF. Osteogenesis: The Development of Bones. Developmental Biology.6th Edition. Sunderland (MA): Sinauer Associates. 2000.

6. MacCropsey L. Show Ring Age Determination - Art, not an Exact Science. Bovine Practitioner. 1973; 8: 61-62.

7. Akpa GN, Abubakar Y, Nwagu BI, Alphonsus C. Genetic and Relationship Estimations of Body Weight and Morphometric Traits in the Red Sokoto Goat. Animal Production Res J. 2009; 4: 321-331.

8. Mitchell T. How to Tell the Age of Goats. Agfact A7.2.2, $2^{\text {nd }}$ edition, Livestock Officer (Goats) Division of Animal Production, Dubbo Onder stepoort Veterinary Institute with Kwazulu-Natal Department of Agriculture and Environment, South Africa. 2003; 60.

9. Dyce KM, Sack WO, Wensing CJG. Textbook of Veterinary Anatomy 4th Edition; Saunders Elsevier. 2010; 7I-78.

10. Akpa GN, Ambali AL, Suleiman IO. Body Conformation, Testicular and Semen Characteristics AS Influenced by Age, Hair Type and Body Condition of Red Sokoto Goat. New York Science J. 2013; 6: I2I-135.

11. Dyce KM, Sack WO, Wensing CJG. Textbook of Veterinary Anatomy Published by Elsevier-Health Sciences Division. 2002; 133-188. 